\title{
Anotaciones para la historia de la poliomielitis en Chile
}

\author{
Enrique Laval $R$.
}

\author{
Notes about the history of poliomyelitis in Chile
}

En el New York Journal del 27 de junio de 1916, se escribía: "la extraña epidemia de parálisis que ha causado catorce muertes durante el mes, ha sido atribuida por los médicos a la persistente humedad de esta primavera y comienzos del verano. Más de cien personas de Brooklyn la padecen y se dice que es endémica en Büdgeport y Filadelfia. Está claro en el pensamiento de la mayoría de los médicos -dice uno de los principales facultativos- que el mal es endémico y que el germen existe en el aire, en el polvo de la ciudad o de cualquier otra parte. El único medio de extirpación es la luz solar. El germen se ha originado probablemente en el largo periodo de humedad y se ha extendido rápidamente, siendo infeccioso pero no contagioso".

Esta fue la primera manifestación pública referente a la epidemia de poliomielitis que se desencadenó en la zona noreste de los Estados Unidos de Norteamérica en el verano de 1916, con 27 mil enfermos, niños en su mayoría, falleciendo seis mil individuos y de los sobrevivientes muchos quedaron inválidos para toda su vida.

Existe evidencia de que se trata de una enfermedad muy antigua, siendo casi seguro que fue conocida por los egipcios, 1600 a.C., pues en los bajo relieve descubiertos en la pirámide Zakkar, se destacan esculpidos claramente en piedra, jóvenes con las secuelas de la enfermedad. En el Renacimiento, las parálisis resultantes de la poliomielitis, se encuentran representadas en "La procesión de los lisiados" de la pintura de Hyeronimus Bosch. A pesar de su aparente antigüedad y confundida durante largos años con diver- sas parálisis, la primera descripción, aunque muy rudimentaria, como una unidad nosológica, fue efectuada en 1784 por el médico inglés Miguel Underwood, en su Tratado de Enfermedades de los Niños. Con posterioridad (1835), Badham, caracterizó mejor la enfermedad, pero fue el médico ortopedista alemán Jacobo Von Heine (1800-1879), quien se dedicó a determinar los diferentes tipos de parálisis encontrados por él y las razones de esas deformaciones, vaciando su experiencia en un trabajo publicado en Stuttgart en 1840 bajo el título de "Observaciones sobre los estados de parálisis de las extremidades inferiores y su tratamiento". Veinte años después, en otra publicación, le dio el nombre que iba a perdurar por largos años, parálisis infantil espinal, porque la observó exclusivamente en los niños o personas que la habían adquirido en la infancia ${ }^{1,2}$.

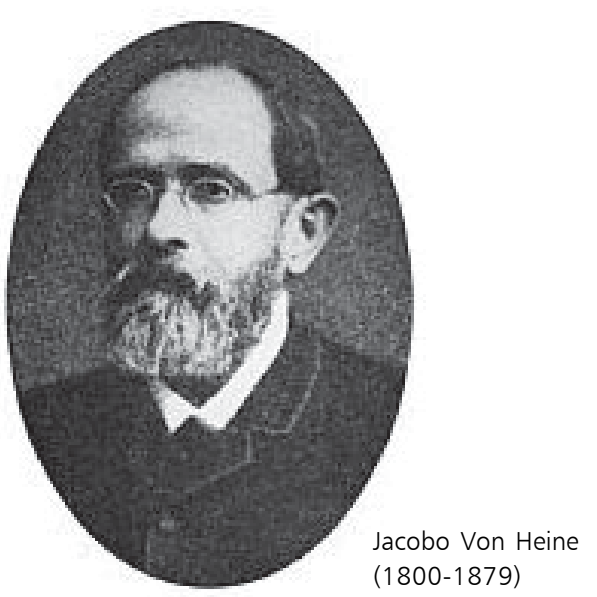

En 1855, Duchenne de Boulogne sur Mer, publicó en París, su célebre memoria "De la paralysie atrophique graisseuse de l'enfance", en la cual dio una descripción bastante aproximada de la enfermedad ${ }^{3}$.

La condición epidémica no se conoció hasta 1890, cuando el pediatra Oskar Medin describió la historia natural de la poliomielitis aguda y las complicaciones neurológicas durante epidemias en Escandinavia, comenzando a denominársele Enfermedad de HeineMedin.

En 1866, Prévost ya había señalado que las parálisis se debían a lesiones en las células de las astas anteriores de la médula espinal, las que según Medin, podía comprometer también la región bulbar.

El carácter epidémico fue confirmado en 1907 por Vickmann. Tras ello se inició el estudio detenido del virus causal, con las experiencias en 1909 de Flexner, Lewis, Landsteiner y Popper, por medio de la inoculación de suspensiones de médula espinal humana en monos, que presentaron el cuadro típico de una parálisis fláccida, confirmando la transmisibilidad del proceso ${ }^{4}$.

Los progresos continuaron en forma lenta hasta el importante descubrimiento en 1949 de Enders, Weller y Robbins, que los poliovirus podían propagarse in vitro en cultivos de tejidos embrionarios humanos de origen no nervioso y en 1950 , de la acción citopatogénica del virus sobre las células cultivadas in vitro.

Estos hallazgos permitirían el desarrollo de vacunas con virus inactivado de Salk (por vía subcutánea) y de virus atenuado de Sabin (oral). 
Bodian fue el primero en reconocer que había tres serotipos diferentes de poliovirus. En 1954, durante una gran epidemia de Toronto, en un estudio sobre más de 800 casos de poliomielitis fue posible separar los tres tipos pertenecientes al grupo de los Picornavirus: el tipo I Brunhilde (denominado así por el nombre de la mona en que fue aislado), el tipo II Lansing (nombre de la ciudad en el estado de Michigan) y el tipo III León (apellido del enfermo, en Los Angeles, California), los que tienen inmunidad cruzada parcial, predominando, claramente, el tipo I.

No existe reservorio extra-humano, estando constituida la fuente infectante por los enfermos clínicos, por los asintomáticos o inaparentes (90 a 95\%) y portadores, que predominan en los lactantes preescolares, eliminándose el virus, fundamentalmente, por las deposiciones ${ }^{1,5}$.

La variedad clínica más frecuente de la enfermedad es la llamada "poliomielitis abortiva (4 a 8\%); en ella hay síntomas generales (fiebre, cefalea, intranquilidad, malestar general) y los que corresponden a la multiplicación viral en el tracto digestivo (odinofagia, náuseas, vómitos, constipación o diarrea). Todo esto dura alrededor de tres días y el diagnóstico de poliomielitis abortiva es muy difícil, aún en períodos epidémicos. En algunos individuos (0,5 al 1\%), después de lo ya descrito, ocurre un período de latencia, seguido de la instalación de un cuadro febril y síndrome meníngeo, con mejoría espontánea al cabo de dos a diez días, constituyendo la llamada "poliomielitis no paralítica o meníngea”. Muy pocos individuos tienen parálisis $(0,5$ a $1 \%)$, las que pueden aparecer después de la sintomatología de las fases abortiva y /o meníngea, o bien, sin ningún síntoma premonitor.

Es necesario señalar que, ocasionalmente, en el curso de la poliomielitis espinal, se producía compromiso de la musculatura respiratoria, con parálisis de los músculos intercostales, constituyéndose una parálisis respiratoria de tipo espinal. En estos casos, la indicación terapéutica precisa era el uso de un sistema de respiración artificial ("pulmón de acero"). Recordemos que el factor más importante que condicionaba la aparición de parálisis en los individuos infectados por los poliovirus era la edad, en el sentido de que a mayor, aumentaba la frecuencia e intensidad de aquellas.

La forma más grave y por consiguiente con más letalidad, era la localización bulbar, en que se alteraban las células de los núcleos grises bulbo-protuberanciales, con aparición de parálisis de nervios craneanos, arritmia cardíaca y respiratoria, la que podía llegar al cese de la respiración y muerte por asfixia. En esta forma de compromiso respiratorio bulbar, no estaba indicado el uso del "pulmón de acero"6-8.

Horstmann y Bodian, en forma independiente, dieron cuenta de la producción de viremia temprana en la infección, lo que explicaría la fase sistémica de la enfermedad y de la diseminación del virus hacia el sistema nervioso central por vías no nerviosas.

La implantación del uso de las vacunas ya mencionadas, especialmente la de Sabin, en forma controlada y con seguimiento eficiente, permitió la erradicación de la enfermedad en muchos países ${ }^{1,5}$.

En Chile, se realizaron numerosos aislamientos de virus polio a partir de 1953. La tipificación de las cepas aisladas reveló la existencia de los tres tipos antigénicos de virus, con predominio del tipo I y las encuestas serológicas demostraron la gran difusión que tenía en nuestro medio la infección por dichos virus, ya que una alta proporción de los sueros poseía anticuerpos neutralizantes, la que aumentaba en relación directa con la edad. La infección se producía precozmente: a los diez años el $90 \%$ de la población tenía anticuerpos contra los tres tipos de virus ${ }^{8}$.

La preocupación por la poliomielitis en el país, si bien antigua, distaba mucho de haber sido sistemática. Inspirado por los doctores Gregorio Amunátegui y Eugenio Díaz Lira, Gonzalo Moraga Fuenzalida le dedica su memoria de licenciado en 1913, relatando haber observado unos 80 casos en dos años "y que la Clínica Nerviosa de Chile (asi la llama), ha practicado tratamiento eléctrico en 53 niños entre 1909 y 1912". Honorio Herrera, que también eligió este tema para su tesis, en 1917, apenas relata siete casos, y en la realizada por Ernesto Prieto Trucco, en el año 1928, hay referencia sólo a los enfermos tratados quirúrgica y ortopédicamente.

El doctor Hugo Lea-Plaza habría sido el primero en describir una epidemia de unos
30 enfermos paralíticos entre noviembre de 1921 y mayo de $1922^{9,10}$.

La información oficial proporcionada por los Anuarios del Servicio Nacional de Salud "descansa en los casos notificados a la autoridad correspondiente, entre los cuales hay un mínimo de enfermos no paralíticos y muy pocos con parálisis transitorias". Según lo señala Ernesto Medina "a partir de estas cifras pudiera pensarse -y tal ha sido la interpretación de algunos autores- que la poliomielitis en Chile fue más bien esporádica en los primeros 30 años del siglo XX; que desde 1935 comenzó a hacerse endémica y a partir de 1945, adquirió un carácter francamente epidémico, con brotes regulares que afectaron de preferencia nuestras grandes agrupaciones urbanas ${ }^{11}$.

En 1948, el profesor Hernán Romero, pronosticaba "con todas las reservas que obliga la inevitable información incompleta, cabe suponer que Chile ha dejado atrás la fase de los casos esporádicos, se halla todavía en la endémica y tal vez en el punto en que las epidemias van adquiriendo volumen progresivo. Si asi fuera, deberían aparecer en el futuro próximo, brotes de consideración y gravedad mayor, con aumento consecutivo de la letalidad y desplazamiento de la distribución hacia edades posteriores".

Fue así como en 1949 la notificación de casos llegó a 292 (tasa de 4,5/100.000), alcanzando a 653 en 1950 (tasa de 10,9/100.000), elevándose nuevamente las denuncias entre 1952-1956. En este último año se comprobaron 719 casos (tasa de 10,4/100.000). La letalidad entre 1949 y 1956, osciló entre 0,9 y $1,3 / 100.000^{10}$.

Hacia fines de 1961 se denunció en Santiago un número creciente de casos, hasta 90 semanales, totalizándose 648 en el país (tasa 8,3/100.000). La aparición de este intenso brote epidémico, obligó en noviembre de aquel año, a iniciar en ese momento la vacunación masiva anti-poliomielítica por vía oral, con un programa elaborado por el Subdepartamento de Protección de la Salud del Servicio Nacional de Salud, con la colaboración del doctor Albert Sabin. Se vacunaron 1.181.006 niños con virus polio tipo I y 1.345 .942 con los virus tipo II y III. Las bases más importantes del programa fueron vacunar el $80 \%$ de los niños entre los tres meses y los siete años de edad; realizando 


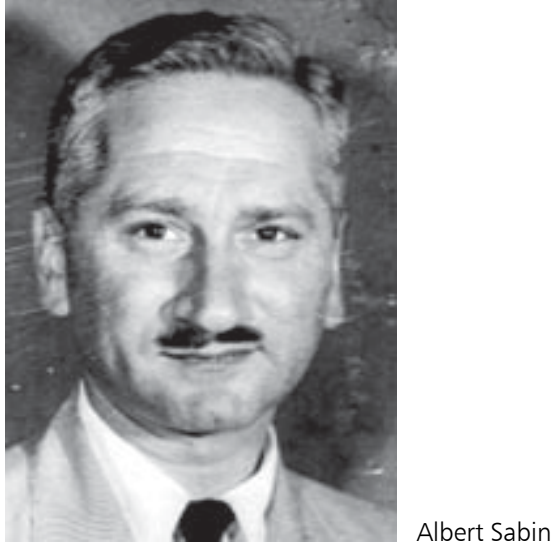

primero la vacunación con el virus tipo I y completándola con los tipos II y III, administrados en forma simultánea, manteniendo los niveles útiles alcanzados por medios de la vacunación de los menores de un año, a partir del tercer mes de vida, con dosis de vacuna trivalente. La vacunación masiva con virus tipo I disminuyó en $72 \%$ el número de casos semanales a los 15 días de vacunación, para alcanzar, al mes siguiente, un 90\% de reducción, lo que puso de manifiesto el éxito del programa por vía oral ${ }^{6,12-14}$.

El último brote de importancia en el país, ocurrió en el período entre agosto de 1969 y agosto de 1970, notificándose 205 casos y 54 fallecidos, con una tasa de morbilidad de 2,2/100.000 ${ }^{10}$. Vergara, Vicente y Banfi hicieron el estudio de este episodio, comprobándose originado por virus polio tipo I. Analizaron 163 casos diagnosticados clínicamente y en 91 aislaron "virus entéricos", de los cuales 84 correspondieron a cepas de poliovirus tipo I. El grupo más comprometido estuvo entre uno y cinco años. Más de $70 \%$ de los casos positivos no tenía vacunación antipoliomielítica o ésta era incompleta. Las zonas central (Valparaíso-Colchagua) y sur (Curicó-Magallanes) fueron las más afectadas. Como los investigadores trabajaron sólo con los confirmados por aislamiento viral, el brote mencionado pudiera aparecer disminuido. Pero no debe olvidarse que la cifra de 163 enfermos parecería muy elevada para Chile, con ya varios años de vacunación anti-poliomielítica $^{15}$.
Finalmente, en 1975, se notificaron los dos últimos casos de poliomielitis en el país ${ }^{10}$.

Chile fue el tercer país del mundo en conseguir la erradicación de la poliomielitis, usando a partir de 1961, la vacuna Sabin: con la aparición de las vacunas orales que utilizan cepas de virus atenuados, seleccionadas por su capacidad de estímulo antigénico, de multiplicación en el hombre, de casi nula o escasa viremia y ausencia de neurovirulencia. Se emplean vacunas trivalentes (mayor cantidad de dosis infectantes para el tipo I, seguida de tipo III y menor de tipo II) que, si bien tienen ventajas administrativas en su uso, poseen el inconveniente de la interferencia entre sí de los virus, con predominio del tipo III, que obliga a separar, por lo menos por dos meses, ( 3 y 5 meses de edad), la entrega de la primera y segunda dosis, efectuando una o más vacunaciones después. La inmunidad parece ser comparable en su duración a la enfermedad natural, por cuanto el mecanismo es similar. En medios hacinados y promiscuos se produce 40 a $80 \%$ de vacunación espontánea interfamiliar por pasaje de virus a otros niños a partir del lactante vacunado, lo que no presentaría problemas de regulación de la neurovirulencia ${ }^{16}$.

Se ha observado la aparición de parálisis poliomielítica asociada a la vacuna oral, con una frecuencia mundial de 1 por 19 millones. En Chile, se comunicó esta eventualidad entre 1986 y 1992, en cuatro lactantes, atendidos en los hospitales Luis Calvo Mackenna y Ezequiel González Cortés ${ }^{17,18}$.

En 1991, se notificó el último caso de poliomielitis en las Américas y en 1994, la Comisión Internacional para la Certificación de la Erradicación de la Poliomielitis, declaró América libre de la transmisión del poliovirus salvaje. La vigilancia exhaustiva de las parálisis fláccidas agudas ha sido un componente clave en el proceso de notificación, ya que si aquélla es de mala calidad, con cobertura de vacunación bajo 95\%, "representa una puerta abierta para la circulación del virus polio, ya sea salvaje (importación) o derivado de la vacuna"19.

En 2003 y 2004, se confirmó la circulación de poliovirus salvaje en países de Asia y África. Nigeria, uno de los seis países endémicos, informó el año 2004, un total de casos cuatro veces superior al 2003, por lo que se inició una campaña de vacunación sin precedentes, con la finalidad de detener la transmisión del virus que amenazaba los avances conseguidos en la erradicación de la poliomielitis del mundo ${ }^{20}$.

\section{Referencias}

1.- Laval M E. Poliomielitis. Curso de Historia de la Medicina. 1957 (inédito).

2.- Top F H. Poliomyelitis. Communicable Diseases. P. 710-77. Ed. The C.V. Mosby Company. St. Louis. USA. 1955.

3.- Devobe G M, Achard C H. Manuel de Médecine. Maladies du System Nerveux. T.III. Paralysie infantile. p. 655-69. Ed. Rueff et Cie. Paris. France. 1897.

4.- Harries E H R, Mitman M. Poliomyelitis Clinical Practice in Infectious Diseases. P. 424-49. Ed. E. and S. Livingstone. LTD. Edinbourgh. Great Britain. 1951.

5.- Mandell G L. Enfermedades Infecciosas. T.II.p. 1435-1442. Poliomielitis. Ed. Médica Panamericana. Bs Aires. Re. Argentina. 1991.

6.- Salcedo S M, Laval R E. Poliomielitis. 1964. (inédito).

7.- Caballero E, Del Río L, Lavín J, Baeza D F, Bolzman R, Topelberg S. Poliomielitis. Experiencia recogida en 1964 en el Hospital Arriarán y su comparación con 60 casos del año 1961. Rev Chil Pediat 1964; 35: 443-6.

8.- Horwitz A. Poliomielitis. Simposio. Rev Méd Chile 1955; 83: 407-33.

9.- Romero C H, Armijo R. Poliomielitis: aspectos epidemiológicos y sanitarios. Rev Chil Pediat 1948; 19: 389-417.

10.- Reppeto D G, Abarca V K, Concha B M, Giaconi G J. Enfermedades Infecciosas Inmunoprevenibles. p. 263-77. Ed. Univ. Católica de Chile. 2003. Santiago de Chile.

11.- Medina L E, Kaempffer A. Poliomielitis en Chile. $1^{\text {a }}$ parte. Rev Chil Pediat 1958, 29: 27-30.

12.- Ristori C, Boccardo H, Borgoño J M, Miranda M. Programa Nacional de Vacunación por vía oral contra la poliomielitis en Chile. 1962. Rev Méd Chile 1964; 92: 77-81.

13.- Boccardo H. La poliomielitis en Chile. Rev Méd Chile 1962; 309-11.

14.- Bravo A L, Ristori C, Alvarado R, Boccardo H, Borgoño J M, Bravo J, Carrillo B, Muñoz S. Vacuna antipoliomielítica oral en Chile tipo I. 
Rev Méd Chile 1962; 90: 839-43.

15.- Vergara M J, Vicente M, Banfi A. Poliomielitis en Chile. Brote de polio. Agosto 1969-Agosto 1970. Estudio de Laboratorio. Rev Chil Pediat 1971; 92: 239-43.
16.- Biblioteca Digital de la Universidad de Chile.- Poliomielitis. Situación actual. P- 14. (sin fecha).

17.- González E, Cordero J. Poliomielitis asociada a vacuna: dos casos clínicos.

18.- Chávez A, Norambuena R X, González E, Castellanos B M. Poliomielitis paralítica asociada a vacuna. Presentación de dos casos. Rev Chil Infect 1999; 16: 127-32.

19.- Vigilancia epidemiológica de las Parálisis Fláccidas Agudas. El Vigía 1999; 2: 16.

20.- Burgos A. Parálisis fláccida aguda. El Vigía 2004; 8: 41. 